\title{
Evaluación del Nivel Lector. Manual Técnico del Tests de Eficacia Lectora (TECLE)
}

\author{
Autores del Manual para \\ Montevideo - Uruguay: \\ Cuadro, A.; Costa, D.; Trías, \\ D. y Ponce de León, $P$.
}

Comentario a cargo de: Prof. Dra. Lilian R. Daset Departamento de Ciencias Cognitivas y de la Salud.

Facultad de Psicología. UCUDAL

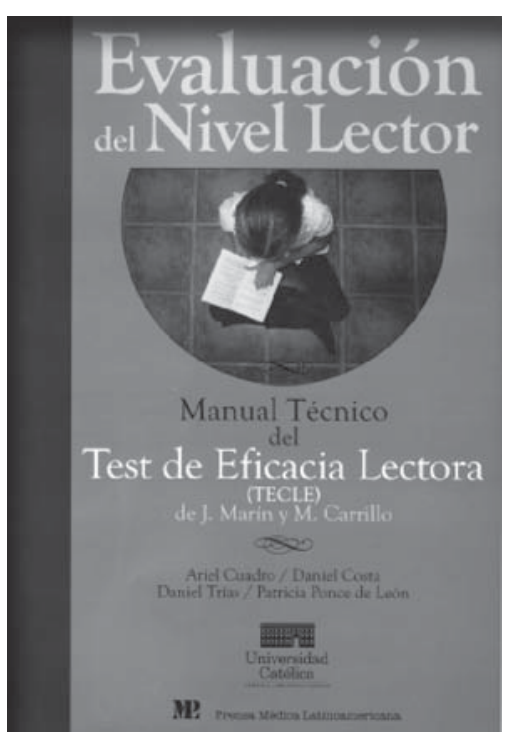

\section{Ficha Técnica}

\begin{tabular}{|l|l|}
\hline Nombre: & Técnica de Evaluación del Nivel Lector (TECLE) \\
\hline Autores: & Marín, J. y Carrillo, M. \\
\hline Editorial: & Prensa Médica Latinoamenricana \\
\hline $\begin{array}{l}\text { Ámbito de } \\
\text { aplicación: }\end{array}$ & Educación Primaria \\
\hline Administración: & Individual o colectiva \\
\hline Baremos: & $\begin{array}{l}\text { Desde segundo a sexto año de colegios católicos de } \\
\text { Montevideo }\end{array}$ \\
\hline
\end{tabular}

Al decir del Prof. Javier Marín (U. de Murcia) " la prueba nació con dos objetivos principales: resultar un instrumento sencillo y útil en la importante y difícil tarea de evaluar la competencia lectora individual, y lograr una medida adecuada de la habilidad para leer". Tales objetivos sin duda se han cumplido con creces con este instrumento y especialmente se ven ampliados por este trabajo que los autores Cuadro, Costa, Trías y Ponce de León hacen de "traerlo" a nuestra región, generando una vía de accesibilidad para los profesionales que trabajan cotidianamente con esta temática.

Los Profesores Marisol Carrillo y Javier Marín, desarrollaron esta prueba y el Dr. Cuadro y su equipo de Uruguay la han adaptado para la evaluación de escolares uruguayos, atendiendo a la necesidad de contar con una forma de valoración de la habilidad lectora - fiable y válida- y fundamentada en los avances que ha alcanzado la Psicología de la Lectura.

El Manual que aquí se presenta contiene tres grandes apartados, además del prólogo y la presentación. La primer parte presenta con claridad y buena síntesis, los principales modelos teóricos sobre la Habilidad Lectora y su evaluación.

La segunda parte se centra en las características generales del instrumento; desde una muy precisa Ficha Técnica; la descripción del mismo; los ámbitos y formas de aplicación y todo lo que 
refiere a los materiales y normativas para la corrección e interpretación de los Baremos.

Una tercera parte está dedicada a la justificación estadística, a partir de los estudios realizados por el equipo uruguayo y los análisis comparativos con otros estudios de relevancia. Este apartado muestra, además, el proceso por el cual se llega a las propuestas de cambio, de la prueba original y la justificación de las mismas.

Además de las necesarias referencias bibliográficas para aquellos que necesiten incursionar en la temática, se agregan dos anexos: el primero contiene los Baremos Normativos para alumnos de nivel primario de la ciudad de Montevideo y que cursan desde el $2^{\circ}$ al $6^{\circ}$ grado, expresados en centiles y con datos de los estadísticos descriptivos básicos (tanto para puntajes directos como para puntajes corregidos). Todo lo que denota un trabajo minucioso y arduo, con una población extensa y una metodología cuidada.

El último de los Anexos contiene la prueba en sí misma, en formato de cuadernillo y con las opciones de respuesta tal cual se plantean al alumno/a, constituyendo un valioso componente del trabajo y el centro de la atención de quienes requieren conocer sobre la habilidad lectora de sus alumnos.

El instrumento está formado por 64 reactivos, donde se formula una frase incompleta y se ofrecen cuatro opciones para completarla, puede ser administrado tanto en forma individual como colectiva. De diagramado muy sencillo y claro para los niños y niñas que lo realizan, también es ágil para la corrección, donde deben ser aplicadas unas operaciones básicas, ofreciendo los Baremos la posibilidad de utilizar tanto las puntuaciones directas como las corregidas.

Es una prueba de cribado, cuyo objetivo final es obtener información sobre el rendimiento en eficacia lectora, entendida como parte de un proceso cognitivo complejo y que a su vez, en sí mismo, implica un dato de relevancia para visualizar dificultades y distinguir entre buenos y malos lectores y poder así, planificar intervenciones ajustadas a grupos que se ubican en niveles similares.

Es sin duda un estudio que nos enorgullece y abre la puerta a muchos otros trabajos -como de hecho ha ocurrido-, tanto de evaluación más especifica, como de intervención y seguimiento. 